\title{
Mobile annotation of geo-locations in digital books
}

\author{
Annika Hinze, Haley Littlewood, and David Bainbridge \\ Dept. of Computer Science, University of Waikato, Hamilton, New Zealand \\ \{hinze, davidb\} @waikato.ac.nz \\ hml15estudents.waikato.ac.nz
}

\begin{abstract}
This demo paper introduces an editor for manual annotation of locations in digital books, using a crowd-sourcing approach. It is the first of its kind and allows book lovers and literary travel enthusiasts to annotate the locations in their digital books on-the-go. We show both a mobile and a desktop version, and briefly explain the linkage to the Digital Library that is holding the digital books.
\end{abstract}

Key words: location, GPS, geo-location in books, semantic markup, semantic annotation, story lines, literary tourism, crowd-sourcing

\section{Introduction}

The importance of places and locations in literature is highlighted by Malcolm Bradbury's observation that a "very large part of our writing is a story of its roots in a place: a landscape, region, village, city, nation or continent" [3]. As a literary device, the role of places and locations is primarily to help explore aspects of identity [4], and so not only may a location in the narrative be real or imaginary, often the boundaries between these are intentionally blurred to create imaginary spaces [7].

Literary tourism is a type of cultural tourism, which focusses on the real-world locations of fictional works and the lives of the authors. It reflects a common desire in many readers to gain a deeper appreciation and understanding of a book they have read- particularly if a book made a significant impact on them. In many ways, modern literary tourism is the successor of the British Grand Tour of Victorian times, in which the upper class would voyage through the cultural centres of Europe [5]. Digital technologies make it easier for the literary tourist of today to engage with geo-information before or after their travel. Furthermore, gaining access to this information in-situ during their travels is technically getting easier now that literary tourists may use smart phones and tablets instead of, or in addition to, books and maps. Currently, many resources for literary tours are relatively static (e.g., web sites providing lists of locations sometimes accompanied by a stylized map). More compelling is the dynamic display of location information as a reader travels (e.g., as in Tipple [8]); however, for this to be supported, geo-location annotation of places and locations in literary works is required.

This paper introduces an editor for manual annotation of locations in electronic books, stored in a digital library and, in doing so, provides a tool for crowd-sourcing the location annotations. Previously, we used simplified automatic annotation using a gazeteer [11], and explored more recently the requirements of creating geo-locations for digital books in three case studies [10]. The editor, called Book Navigator, offers both a mobile app version and a desktop-based interface for creating geo-location annotations, which are stored in addition to the eBook in Greenstone [13]. The remainder of the 
paper shows a brief walk-through of the mobile and desktop system (Section 2) along with a overview of the system architecture and implementation in Section 3. We discuss related approaches in Section 4, and conclude with a short summary in Section 5.

\section{Walk-through}

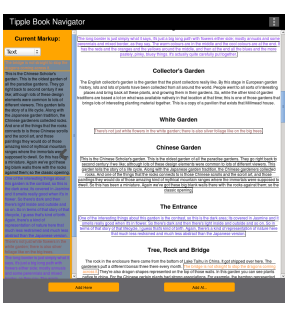

Fig. 1: Book view

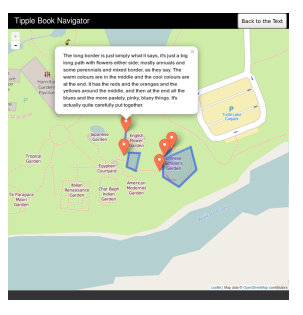

Fig. 2: Map view

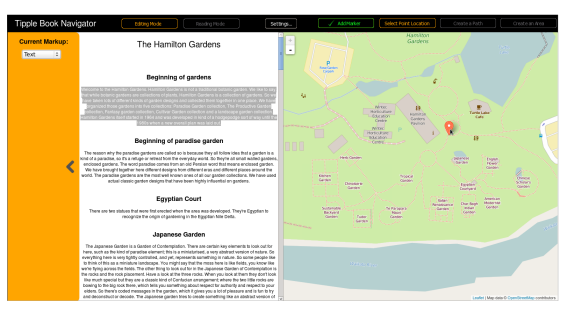

Fig. 3: Desktop view with book and map

Figs. 1 and 2 show screenshots of the mobile Book Navigator interface for annotating locations in books in-situ, and Fig. 3 shows the desktop interface. In the example shown, a user visiting the Hamilton Gardens is annotating a book about the Paradise Gardens on their mobile device, and online ex-situ using the desktop interface. Fig. 1 is the document view during the annotation of a short paragraph. Navigation through the book is done through up/down scrolling; annotation is initiated through a long-click on a text element. In this screen, one can see that the user is able to select an area or a path (two buttons at the lower end of the screen) to annotate. Fig. 2 shows the equivalent map view based on the user's current location. A path is defined through a number of locations; its direction is defined through the order in which the locations are selected. Users can either annotate a locations with their current position (based on GPS) or with distant locations selected via the map. Fig. 3 shows a screenshot of the desktop interface: all locations have to be explicitly selected on the map for annotation. The larger screen makes it possible to show both text and map at the same time.

\section{Architecture and Implementation}

Fig. 4 shows the architecture of the editor software for annotating eBooks with locations. The map information is imported from Open Street map, the eBooks are held in a Greenstone Digital Library. The display component allows a user to select an eBook from a collection, and display the text in the Map Display. The user can navigate through the text of the book; via the

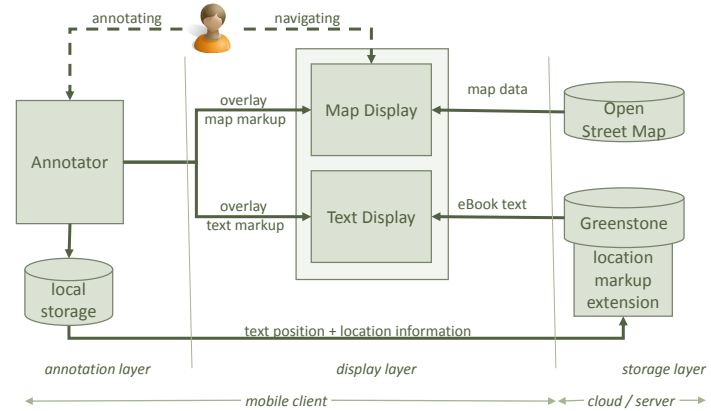

Fig. 4: Architecture of mobile annotator 
Annotator component, they can then select a part of the text and assign location markers - see Fig. 5 for the conceptual diagram of the relationships between marker, location markup, text annotation, and book. The annotations (i.e., text positions and location information) are first stored locally on the mobile device (to ensure independence from a server connection) and can be uploaded later to the digital library running on server side or to a cloud storage for exchange. This architecture can also be run self-contained

on a smart phone using the mobile configuration of Greenstone [2]. We currently support (see Fig. 5) markers for areas (polygon), paths (polyline), single GPS locations (point) and gateways to indicate entries and exists (directed graph). Text elements (e.g., words, phrases or paragraphs) can have several locations assigned. The annotation only stores the beginning and the end of an annotation and does not refer to the text content itself.

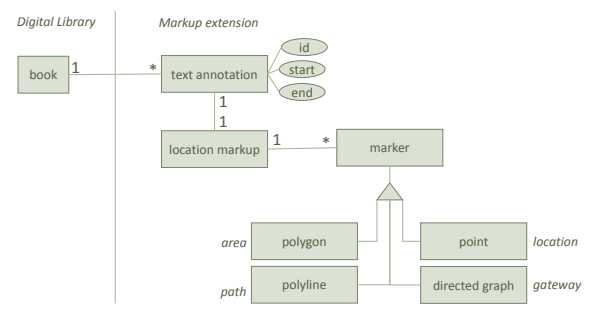

Fig. 5: Conceptual design

\section{Related work}

Maps of literary spaces are typically hand-crafted, i.e., the locations are collected through literary analysis and then entered into maps. Examples of such mappings are found in the "Literary Atlas of Europe" [17] and the "Atlas of Literature" [3]. Older projects are "Projekt Historischer Roman" (mapping 6700 German language novels) and "Atlas das Literaturas Regionais do Brasil" (mapping 550 Brazilian literary works); however, neither of these provide open sources nor allow further location annotations [16]. The Gutenkarte automatically identifies geo-locations in classic texts from project Gutenberg (http: //www.gutenberg.org/) and the MetaCarta API. Its approach is similarly simplistic and limited as our work using a gazetteer of place names [11].

Literature analysis has long focussed on the temporal aspects of a narrative. In recent decades, this has shifted to a focus on spatial aspects [6], which has been referred to as a spatial turn [18] and topographical turn [19]. Bachti uses the concept of chronotopoi-elements of space-time of a story—which form the foundation for "showing and representing" events in a literary text, e.g., on maps or timelines [1].

Piatti et al. [16] note that literary geography is based on individual readings and acknowledge a double uncertainty in both the primary material (uncertainty of location information in the text) and in the methodology (location annotation). We embrace his uncertainty and the highly individually biased nature of literary location annotations through our crowd-sourcing approach. Inspiration for our annotation interface was drawn from semantic annotation tools [12]. The native support for semantics in digital libraries (e.g., JeromeDL [14], Greenstone [9]) typically abstracts at the document level and these works did not provide the type of fine grained access required here. In fact, most systems that provide location-based information either use automatically collected coordinates [15] or expert manual location markup [3, 17]. 


\section{Summary}

This paper introduced our editor prototype for creating mobile annotation of geo-locations in eBooks. By storing the books and suggested annotations in a digital library, we provide an environment that allows the crowd-sourcing of this information. We investigated related work on mapping literature and distinguished our crowd-sourcing approach from the work of literary cartographers.

\section{References}

1. M. Bachtin. Formen der Zeit und des Chronotopos im Roman. In E. Kowalski and M. Wegner, editors, Untersuchung zur Poetik und Theorie des Romans. Aufbau Verlag, 1986 (1937/38).

2. D. Bainbridge, S. Jones, S. McIntosh, I. H. Witten, and M. Jones. Beyond the client-server model: Self-contained portable digital libraries. In Digital Libraries: Universal and Ubiquitous Access to Information, pages 294-303. Springer, 2008.

3. M. Bradbury and R. Ahrens. The atlas of literature. De Agostini Editions London, 1996.

4. P. Brown and M. Irwin. Literature and Place, 1800-2000. Peter Lang, 2008.

5. S. J. Cunningham and A. Hinze. Supporting the reader in the wild: identifying design features for a literary tourism application. In SIGNZ Human-Computer Interaction (CHINZ), 2013.

6. E. Fischer-Lichte. The shift of a paradigm: From time to space? introduction. In XIIth Congress of the Int. Comparative Literature Association, volume 5, pages 15-18, 1988.

7. W. Fluck. Theories and methods imaginary space; or, space as aesthetic object. Space, Place, Environment, 15:15, 2004.

8. A. Hinze and D. Bainbridge. Listen to Tipple: creating a mobile digital library with locationtriggered audio books. In TPDL'2012, pages 51-56. Springer, 2012.

9. A. Hinze, G. Buchanan, D. Bainbridge, and I. Witten. Semantics in Greenstone. In S. R. Kruk and B. McDaniel, editors, Semantic Digital Libraries, pages 163-176. Springer, 2009.

10. A. Hinze, S. J. Cunningham, and D. Bainbridge. The challenge of creating geo-location markup for digital books. In under reveiw (submitted to TPDL 2015).

11. A. Hinze, X. Gao, and D. Bainbridge. The TIP/Greenstone bridge: A service for mobile location-based access to digital libraries. In Research and Advanced Technology for Digital Libraries, pages 99-110. Springer, 2006.

12. A. Hinze, R. Heese, M. Luczak-Rösch, and A. Paschke. Semantic enrichment by nonexperts: usability of manual annotation tools. In The Semantic Web-ISWC 2012, pages 165-181. Springer, 2012.

13. H. W. Ian, B. David, and D. Nicols. How to build a digital library. Morgan Kaufman Publishers, 2009.

14. S. Kruk, M. Cygan, A. Gzella, T. Woroniecki, and M. Dabrowski. JeromeDL: The social semantic digital library. In S. R. Kruk and B. McDaniel, editors, Semantic Digital Libraries, pages 139-150. Springer Berlin Heidelberg, 2009.

15. B. Pat, Y. Kanza, and M. Naaman. Geosocial search: Finding places based on geotagged social-media posts. In International World Wide Web Conference. ACM, 1915.

16. B. Piatti, A.-K. Reuschel, and L. Hurni. Literary geography-or how cartographers open up a new dimension for literary studies. In International Cartography Conference, 2009.

17. A.-K. Reuschel, B. Piatti, and L. Hurni. Mapping literature. the prototype of "A Literary Atlas of Europe". In Proceedings of the 24 th International Cartographic Conference, 2009.

18. E. W. Soja. Thirdspace: Journeys to los angeles and other real and imagined places. Transactions of the Institute of British Geographers, 22(4):529-540, 1997.

19. S. Weigel. On the 'topographical turn': Concepts of space in cultural studies and Kulturwissenschaften. a cartographic feud. European Review, 17(01):187-201, 2009. 